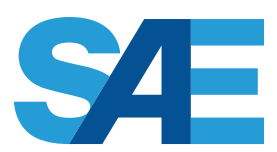

INTERNATIONAL。

\title{
Primary Reference Fuels (PRFs) as Surrogates for Low Sensitivity Gasoline Fuels
}

\section{Vijai Shankar Bhavani Shankar, Muhammad Sajid, Khalid Al-Qurashi, Nour Atef, Issam Alkhesho, Ahfaz Ahmed, Sukho Chung, and William Roberts}

King Abdullah University of Science and Technology

\section{Kai Morganti}

Saudi Aramco

\section{Mani Sarathy}

King Abdullah University of Science and Technology

CITATION: Bhavani Shankar, V., Sajid, M., Al-Qurashi, K., Atef, N. et al., "Primary Reference Fuels (PRFs) as Surrogates for Low Sensitivity Gasoline Fuels," SAE Technical Paper 2016-01-0748, 2016, doi:10.4271/2016-01-0748.

Copyright (C) 2016 SAE International

\begin{abstract}
Primary Reference Fuels (PRFs) - binary mixtures of n-heptane and iso-octane based on Research Octane Number (RON) - are popular gasoline surrogates for modeling combustion in spark ignition engines. The use of these two component surrogates to represent real gasoline fuels for simulations of HCCI/PCCI engines needs further consideration, as the mode of combustion is very different in these engines (i.e. the combustion process is mainly controlled by the reactivity of the fuel).
\end{abstract}

This study presents an experimental evaluation of PRF surrogates for four real gasoline fuels termed FACE (Fuels for Advanced Combustion Engines) A, C, I, and J in a motored CFR (Cooperative Fuels Research) engine. This approach enables the surrogate mixtures to be evaluated purely from a chemical kinetic perspective. The gasoline fuels considered in this study have very low sensitivities, $\mathrm{S}$ (RON-MON), and also exhibit two-stage ignition behavior. The first stage heat release, which is termed Low Temperature Heat Release (LTHR), controls the combustion phasing in this operating mode. As a result, the performance of the PRF surrogates was evaluated by its ability to mimic the low temperature chemical reactivity of the real gasoline fuels. This was achieved by comparing the LTHR from the engine pressure histories. The PRF surrogates were able to consistently reproduce the amount of LTHR, closely match the phasing of LTHR, and the compression ratio for the start of hot ignition of the real gasoline fuels. This suggests that the octane quality of a surrogate fuel is a good indicator of the fuel's reactivity across low (LTC), negative temperature coefficient (NTC), and high temperature chemical (HTC) reactivity regimes.

\section{Introduction}

The development of internal combustion engines that offer higher efficiency without compromising on emission standards has been an area of intense research. Low Temperature Combustion engines have received widespread interest in this regard $[\underline{1}, \underline{2}, \underline{3}, \underline{4}, \underline{5}, \underline{6}, \underline{7}, \underline{8}, \underline{9}$, 10]. Many strategies have been explored and concepts such as Homogeneous Charge Compression Ignition (HCCI), Pre-mixed Charged Compression Ignition (PCCI) and Reactivity Controlled Compression Ignition (RCCI) engines have received attention over the last two decades. There are many challenges to their use in automotive vehicles, with the most important being the control of the combustion phasing and operation of the engine at high loads $[\underline{1}, \underline{2}]$.

Gasoline fuels with two-stage ignition behavior are well suited for use in Low Temperature Combustion engines $[\underline{6}, \underline{10}]$. These fuels exhibit low octane sensitivities (the difference between Research Octane Number (RON) and Motor Octane Number (MON) discussed in detail later) due to their pronounced NTC behavior. They also exhibit low temperature heat release (LTHR), which in turn influences the hot ignition and hence the combustion phasing. The LTHR of the fuel/air mixture depends on the equivalence ratio, temperature-pressure history of the mixture, composition and concentration of the residual gas (EGR), fuel/air mixture homogeneity, engine wall temperatures, along with any fuel charge cooling effects $[\underline{2}, \underline{4}]$. The ability to control any of the above parameters enables the control of combustion phasing. The cost of producing fuels that exhibit two stage ignition is also likely to be cheaper, since octane enhancing components (e.g. aromatics, alkylates and oxygenates) are required in lesser quantities. 
Computational simulations are essential for gaining insights into the influence of these physical parameters on fuel oxidation and autoignition behavior, without the need for exhaustive experiments. This can accelerate the development of new engine-fuel concepts. The use of simulations also provides access to information that cannot readily be measured through experiments, such as the in-cylinder temperature distribution, and the mechanisms through which instability and subsequent misfires occur [11]. The accuracy of such predictions is however dependent on the ability chemical kinetic models to replicate the actual behavior of the fuel. The task of developing chemical kinetic models of real gasoline fuels, which are made of hundreds of different hydrocarbon species, is impossible at present [12]. Surrogate compositions made of few chemical species that emulate certain characteristics of the real gasoline fuel have therefore been used for modeling.

A range of different target properties have been suggested for formulating surrogate fuel compositions. Nonetheless, the properties themselves must be assigned keeping the end applications in mind [13]. Pitz et al. [14] suggested that for HCCI engines, the crank angle at which $50 \%$ of the fuel is burned (CA50) would be an important target since the work output of the engine was particularly sensitive to this parameter. These authors also point out (based on the work of Dec and Sjöberg [4] ) that CA10 would be a more appropriate target since it is easier to predict with present chemical kinetic mechanisms and simple engine models. Ranzi [13] also suggested a number of physical and chemical properties that surrogate fuels should match, including liquid-gas equilibrium, viscosity, thermal stability, chemical classes, octane number, etc. For jet fuels, Dooley et al. [15] recommended the hydrogen-to-carbon ratio $(\mathrm{H} / \mathrm{C})$ ratio as an important property since it ensures the regulation of enthalpy of reaction, which influences the adiabatic flame temperature and other flame behavior. The properties identified as relevant to gasoline fuels in Ahmed et al. [16] were the $\mathrm{H} / \mathrm{C}$ ratio, density, compositional characteristics considering both carbon class (paraffin, iso-paraffin, olefins, naphthenes, and aromatics), and carbon type (primary, secondary, and tertiary), distillation curve, and research octane number (RON). Compositions with varied number of species and models with different levels of complexity have been formulated based on the criterion stated above for simulating gasoline combustion $[\underline{12}, \underline{16}, \underline{17}, \underline{18}, \underline{19}, \underline{20}, \underline{21}, \underline{22}, \underline{23}, \underline{24}]$.

Primary Reference Fuel (PRF) based on the Research Octane Number (RON) of a fuel is one of the widely adopted surrogate for historical reasons, and an extensive effort has been made over the years for the development of its chemical kinetic model $[\underline{25}, \underline{26}, \underline{27}, \underline{28}, \underline{29}]$. PRF based on RON is representative of the fuel's auto-ignition behavior at one specified test condition [30] and may or may not match the other target parameters stated earlier. The operating regimes of modern gasoline and HCCI engines are quite different from the RON measurement conditions, and hence the behavior of PRF usually varies from that of the gasoline. The use of surrogates that match the fuel's Octane Index (OI = RON - KS) would be more appropriate for simulating its autoignition behavior [31]. Sensitivity (S), is the difference between the RON and the Motor Octane Number (MON). $\mathrm{K}$ is an empirical constant independent of the fuel and dependent on the engine operating condition [32]. However, for gasoline fuels with zero sensitivity $(\mathrm{S}=\mathrm{RON}-\mathrm{MON}=0)$ there is no a priori reason to assume that PRF would exhibit different oxidation and auto-ignition behavior at any engine condition. Motor Octane Number (MON) stated above is the measurement of knocking quality of a fuel when the intake air temperature and operating speed of the engine is greater than that of RON [33]. The timing of spark, unlike the RON test, is variable.

Sarathy et al. [24] recently compared the ignition delay times (IDT) of PRF 84, and two low sensitivity full boiling range gasoline fuels with RONs of 84 (FACE A and FACE C) in low and high pressure shock tubes (LPST and HPST), as well as a rapid compression machine (RCM). The operating temperatures of these devices were complimentary to each other with small overlaps. This allowed for the comparison of IDTs across temperatures where ignition is controlled LTC (630K -740 K), NTC (740 K - $900 \mathrm{~K})$ and HTC $(>900 \mathrm{~K})$ reactions. The ignition delay times were identical for temperatures above $740 \mathrm{~K}$, which covered the NTC and HTC regions. The authors observed deviations at lower temperatures ranging from $630 \mathrm{~K}$ to $740 \mathrm{~K}$, which corresponds to the region where the ignition is driven by LTC reactions. The FACE gasoline fuels were consistently less reactive than PRF 84. Measured and simulated pressure traces of PRF 84, FACE A, and FACE C in air at $658 \mathrm{~K}, 20$ bar, and equivalence ratio $(\varnothing)$ of 1 in a RCM is presented in Fig. 1 (reproduced with permission from Sarathy et al. [24]). The variation of IDT in this region was attributed, with the help detailed kinetic models, to the differences in ignition controlling reactions between PRF 84 and the FACE fuels. FACE A, and C were modelled using 5, and 6 component surrogate mixtures arrived at using a number of target properties.

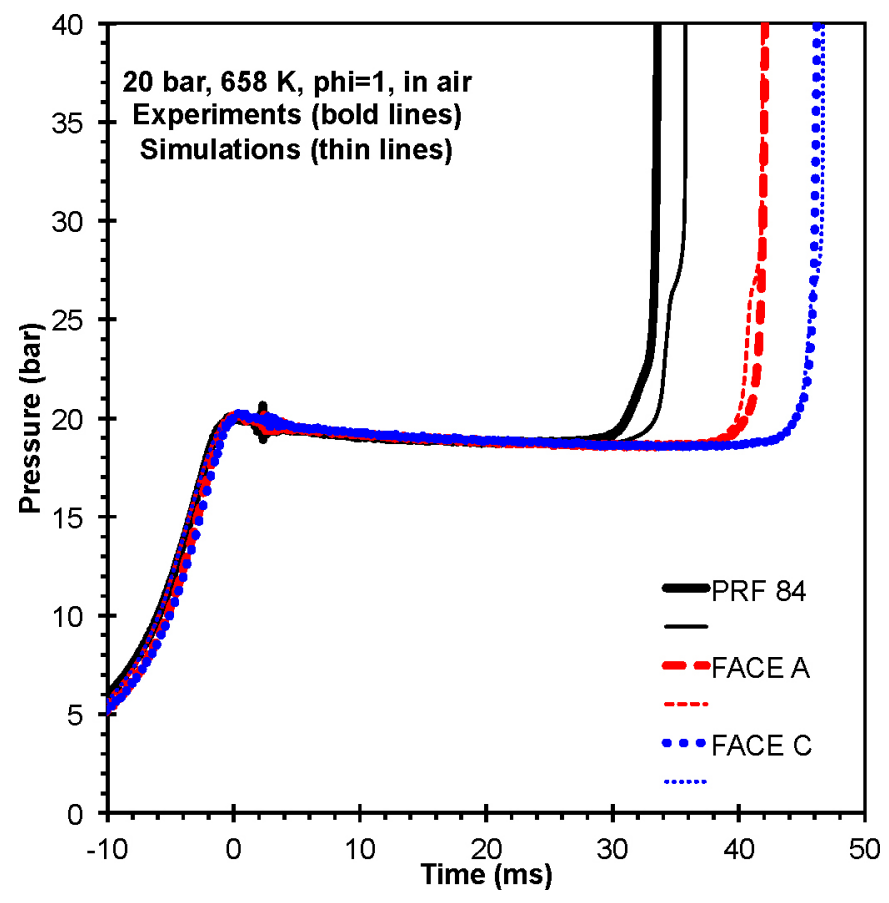

Figure 1. (Reproduced with permission from Sarathy et al. [24])Experimental (bold) and simulated (thin) pressure traces of PRF 84, FACE A, and FACE C in a RCM

The objective of this study is to experimentally investigate and verify if the differences in the low temperature oxidation pathways between PRFs and FACE gasoline fuels have significantly impact the ability of PRF surrogate mixtures to replicate FACE A and FACE C's behavior under engine-like conditions. The study was also extended 
to two more FACE gasoline fuels, FACE I and FACE J, as they also exhibit very little sensitivity and have RONs that are similar to that of straight-run naphtha; a potential fuel HCCI/PCCI applications [34].

\section{Experimental Setup}

The low temperature reactivity of the FACE gasoline fuels and their PRF surrogates were evaluated based on the calculated gross LTHR using pressure data and measured carbon monoxide concentrations from a motoring Cooperative Research Fuels (CFR) engine. The standard engine can be operated at variable compression ratios (CRs) ranging from 4 to 16 with a resolution of 0.1 . This approach can be used to replicate a variable volume reactor, as observed elsewhere in the literature. For example, Sahetchian et al. studied the oxidation of n-butane and n-heptane in motored CFR engine. Leppard also used a similar technique to study the oxidation and auto-ignition chemistry of several hydrocarbons. Similarly, Yang et al. used this technique to examine the oxidation chemistry of cycloalkanes, while Zhang et al. used it for the study of auto-ignition n-heptane/C7 esters and nheptane/1-butanol binary mixtures $[\underline{35}, \underline{36}, \underline{37}, \underline{38}, \underline{39}, \underline{40}, \underline{41}, \underline{42}]$. The schematic and the operating conditions of the CFR engine are presented in Fig. 1 and Table 1, respectively.

The carburetor in the standard CFR engine was replaced with a port-injection system. The intake air was chilled $\left(11 \pm 2{ }^{\circ} \mathrm{C}\right)$ and the flow was measured by an Elster mass flow meter. After this point, the air was re-heated to the desired temperature. The fuel was injected into the hot air stream at 5 bar, which enabled the immediate vaporization and rapid mixing that is required to produce a reasonably homogeneous fuel/air mixture inside the cylinder. The engine was operated at a constant speed of $600 \mathrm{rpm}$ without any boosting and at $\varnothing=0.5$ (lambda $=2)$. A Bosch Universal Exhaust Gas Oxygen (UEGO) sensor positioned in the exhaust was used to determine the equivalence ratio. The compression ratio was initially increased to the point where auto-ignition occurred in order to set the required equivalence ratio by adjusting the injection pulse width.
The compression ratio of the engine was then decreased to the point where no low temperature reactivity was observed. This was established based on the carbon monoxide $(\mathrm{CO})$ concentration in the exhaust using an AVL SESAM i60 Fourier Transform Infrared spectrometer (FTIR). The compression ratio was then increased in small increments to the point just before auto-ignition. The FTIR measures multiple gas phase components of the exhaust at a frequency $1 \mathrm{~Hz}$ with a spectral resolution of $0.5 \mathrm{~cm}-1$ and response time of 1 second in real time operation.

The in-cylinder pressure at each point was recorded with an AVL GH $14 \mathrm{D}$ pressure transducer with a resolution of 0.1 crank angle degrees $\left({ }^{\circ} \mathrm{CA}\right)$. The top dead center (TDC) position at the end of compression is taken to be $0^{\circ} \mathrm{CA}$. The pressure data used for computing LTHR was averaged over 100 cycles and further smoothed by computing moving averages of 5 points. The gross heat release rate (HRR) was computed using a simple first law as presented in Eq. 1.

$$
\frac{d Q}{d \theta}=\frac{V \frac{d P}{d \theta}+\gamma P \frac{d V}{d \theta}}{\gamma-1}
$$

$\frac{d q}{d \theta}$ is the heat release rate per crank angle degree, $\mathrm{P}$ is the in cylinder pressure, $\mathrm{V}$ is the instantaneous volume, and $\gamma$ is the ratio of specific heats is a function of temperature. $C_{p}$ for air was calculated from NASA polynomials [녀]. The net heat release rate, which includes heat loss to the wall, was avoided for the sake of simplicity. Its inclusion would not have significant effect on the comparison as most heat transfer correlations for an engine operating under same conditions is exclusively dependent on the cylinder pressure and bulk gas temperature [44]. Thus, the heat lost to the wall would be proportional to gross heat release rate. The temperature used for computing $C_{p}$ and subsequently $\gamma$ was calculated from the smoothed pressure data using ideal gas law. The dependence of $C_{p}$ on temperature is presented in Eq. 2.

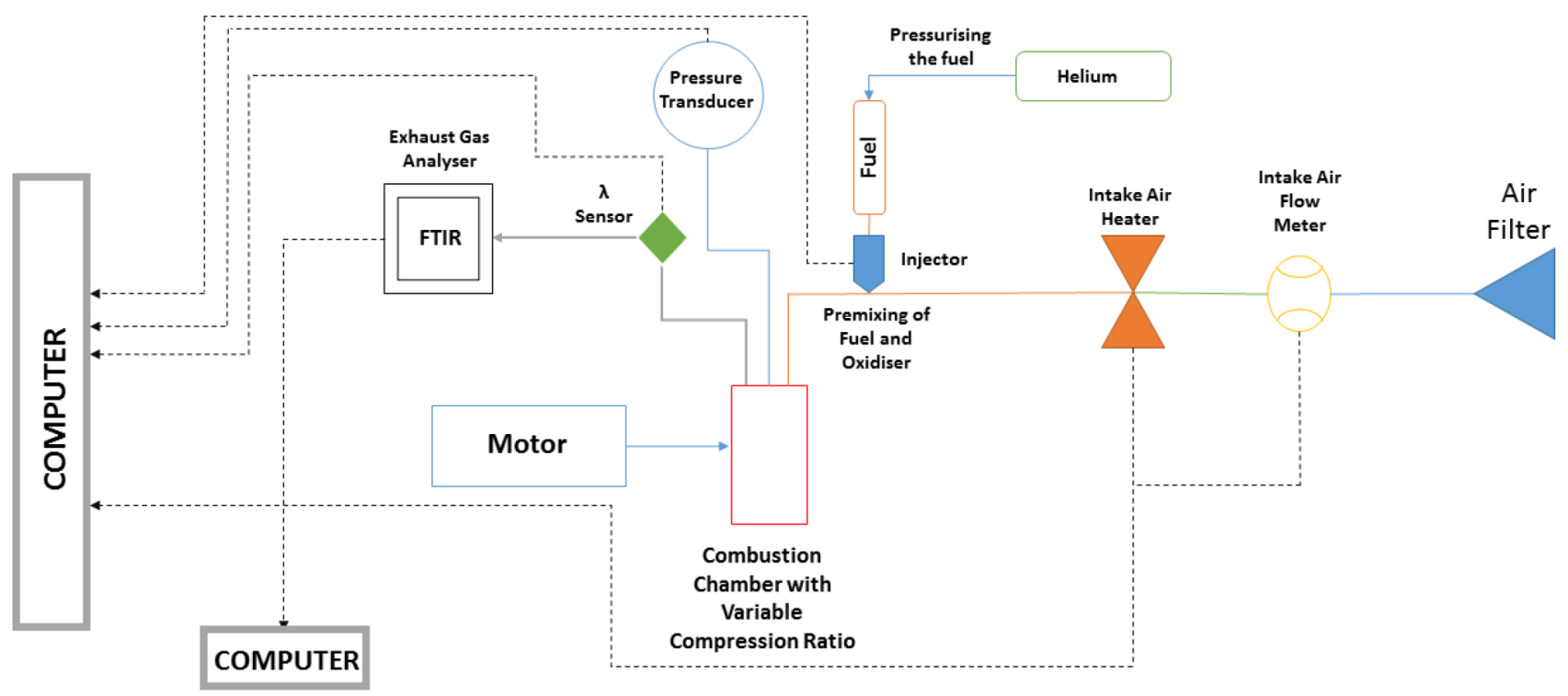

Figure 2. Schematic of the modified CFR engine 
The operation of the CFR engine is this mode allowed us to evaluate the relative LTC, NTC, and HTC of the fuels without the differences in their physical properties affecting the comparison. The lack of intake air boosting does not allow us to evaluate the pressure dependence on reactivity of different fuel mixtures.

Table 1. Engine specifications and operating conditions

\begin{tabular}{|l|l|}
\hline Engine Type & Single Cylinder CFR \\
\hline Injection System & Port Fuel Injection \\
\hline Bore & $82.55 \mathrm{~mm}$ \\
\hline Connecting Rod & $254 \mathrm{~mm}$ \\
\hline Compression ratio & Variable from $4: 1$ to $16: 11$ \\
\hline Speed & $600 \mathrm{rpm}$ \\
\hline Intake Air Temperature & $150 \pm 2{ }^{\circ} \mathrm{C}$ \\
\hline Equivalence Ratio & 0.5 \\
\hline
\end{tabular}

\section{Fuels}

The fuels tested in this study are full boiling gasoline fuels referred to as FACE A, C, I, and J, along with their RON based PRF surrogates. The FACE gasoline fuels were designed by the Coordinating Research

Table 2. Properties of FACE Fuels

\begin{tabular}{|c|c|c|c|c|}
\hline & FACE A & FACE C & FACE I & FACE J \\
\hline RON & 83.9 & 84.3 & 70.15 & 73.8 \\
\hline MON & 83.5 & 83.0 & 69.5 & 70.1 \\
\hline S & 0.4 & 1.3 & 0.65 & 3.7 \\
\hline n-paraffins \% & 11.65 & 24.43 & 14.39 & 31.64 \\
\hline iso-paraffins \% & 85.99 & 69.73 & 74.54 & 33.64 \\
\hline cyclo-paraffins \% & 1.61 & 0.36 & 3.30 & 2.29 \\
\hline Aromatics \% & 0.38 & 3.92 & 1.15 & 31.69 \\
\hline Olefins \% & 0.21 & 1.27 & 6.35 & 0.60 \\
\hline Carbon wt.\% & 83.99 & 84.58 & 84.14 & 86.24 \\
\hline Hydrogen wt.\% & 16.01 & 15.57 & 15.86 & 13.76 \\
\hline
\end{tabular}

Council, Inc. [44] and supplied by Conoco Philips Chemical company. The octane numbers and select physical properties of the FACE fuels are presented in Tables 2. PRF 84 was used as the surrogate for FACE A, and C while PRF 70 was used for FACE I, and J. The detailed physical and chemical analysis of FACE gasoline fuels are available in Ref [44]. FACE A, C, and I are highly paraffinic while FACE J contains about $32 \%$ aromatics by mass. All the fuels exhibit very little sensitivity, which is due to the high paraffinic nature of the FACE A, C and I, thereby leading to a pronounced NTC region [흐]. Although FACE J has a high aromatic content, which usually leads to high sensitivities, the relative composition of $\mathrm{n}$-paraffins to iso-paraffins is quite different for the other three fuels.

The higher concentration of straight chain paraffins compensates for the lack of NTC chemistry associated with aromatics. The higher aromatic content FACE $\mathrm{J}$ also has a predictable effect on its distillation curve and its final boiling point, which is much greater than the others fuels. The density of FACE J follows the same trend, while heat of combustion and API gravity is lower than other fuels

\section{Ignition Delay Time Simulations}

Ignition delay times for PRF 82, PRF 84, PRF 86, along with binary mixtures of butane (69.90 mol.\%) and pentane (30.10 mol. \%), and isopentane $(72.87 \mathrm{~mol} . \%)$ and pentane $(27.13 \mathrm{~mol} . \%)$ in air at $\varnothing=$ 0.5 were simulated in a homogenous constant volume batch reactor using CHEMKINPRO [46] for pressures of 20 and 50 bar and temperatures of $650 \mathrm{~K}$ to $1250 \mathrm{~K}$. The IDT of PRFs were simulated using the gasoline surrogate mechanism from Lawrence Livermore National Lab (LLNL) [19] and mixtures of C4 and C5 species using a well validated pentane mechanism by Bugler et al. [47]. The thermochemistry and the rates of reactions involving iso-octane were updated using the new rules provided in Bugler et al.[47].

\section{Experimental Results}

\section{Reactivity Regimes}

$\mathrm{CO}$ concentrations measured in the exhaust for FACE fuels and their respective PRF surrogates are presented as a function of compression ratio in Fig. 3.a and Fig. 3.b. The start of low temperature reactivity an be identified by the presence of $\mathrm{CO}$ in the exhaust. The $\mathrm{CO}$ concentrations presented are averages of 20 data points. The increase in $\mathrm{CO}$ concentration with increasing compression ratio signals an increase in the low temperature reactivity. The low temperature reactivity starts at CR 5.5 for FACE A, C, and PRF 84. The start of reactivity occurs much earlier at CR 5, as expected for FACE I, J, and PRF 70. Further increases in the compression ratio beyond CR 6.5 for the former three and CR 6 for the later three does not significantly enhance the reactivity rapidly. The plateauing of the $\mathrm{CO}$ profile indicates that the temperature in the combustion chamber as well as the heat released from fuel oxidation pushes the fuel/air mixture from the LTC region into the NTC region of reactivity, but the temperatures and pressures at these compression ratios are not high enough for the fuel/air mixtures to move into HTC. The chemistry that gives rise to NTC region is reasonably well established [36]. This region is more pronounced for FACE A, C, and PRF 84 as expected due to their higher RON. The reactivity then again rises as further increase in compression ratio helps the fuel/air mixture overcome the NTC region transition into the HTC region as the $\mathrm{CO}$ concentration begins to increase again. The HTC reactivity subsequently becomes large enough, leading to ignition as seen by the drop in $\mathrm{CO}$ concentration (which is converted to $\mathrm{CO}_{2}$ ). However, in both cases there is a small variation at the start of hot ignition. FACE A's auto-ignition occurs CR 0.1 later than FACE C and PRF 84, while PRF 70's auto-ignition occurs 0.1 later than FACE I, and J. This might be due to the high sensitivity of LTHR, which controls auto-ignition, to the operating conditions and the inevitable variations of the test conditions 


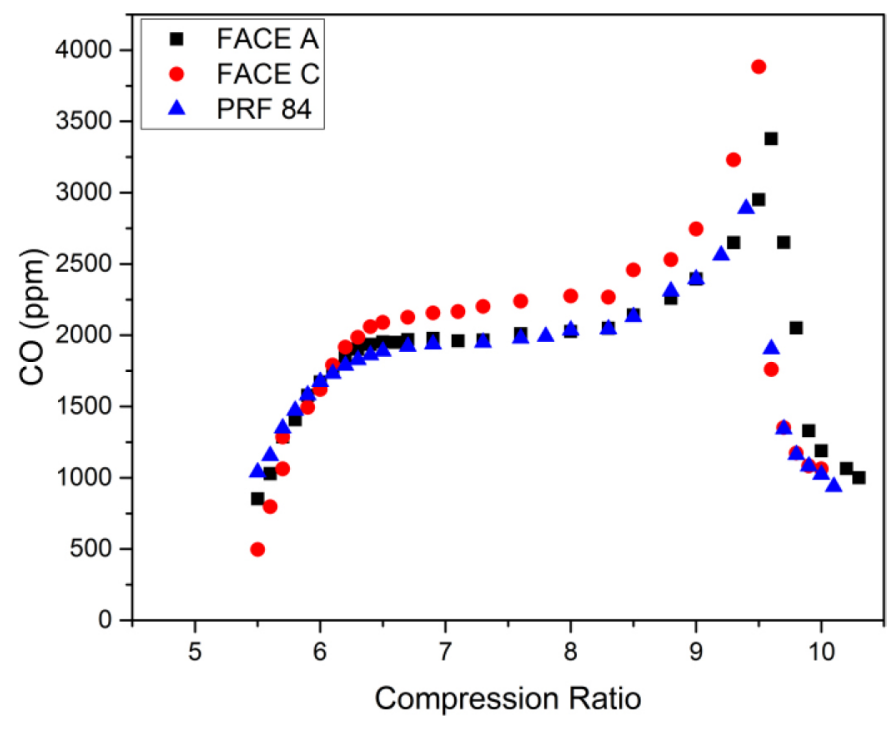

Figure 3.a. CO concentrations measured at different CR of FACE A, C, and PRF 84. The rise, plateau, and the fall of $\mathrm{CO}$ indicate the low temperature, negative temperature coefficient and high temperature reactivity regimes.

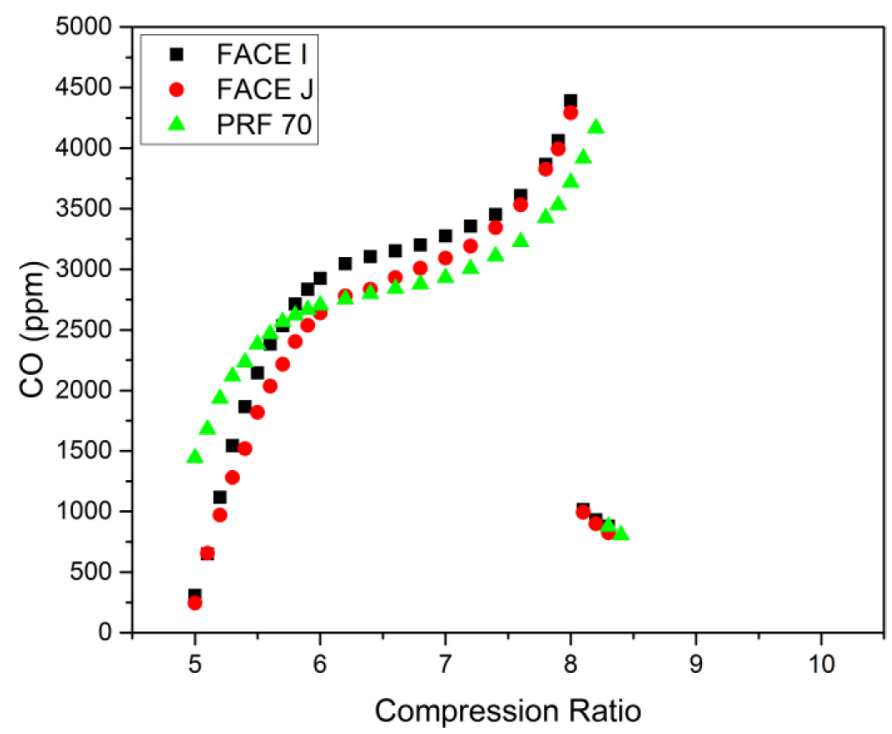

Figure 3.b. CO concentrations measured at different CR for FACE I, J, and PRF 70

Figure 3.c presents the $\mathrm{CO}$ profiles of PRF 70 measured on three different days. The compression ratio for the start of hot ignition is different on each day and deviates by $0.1{ }^{\circ} \mathrm{CA}$. This suggests that the PRF surrogates reproduce the quanta of LTHR of gasoline fuels within variability limits. The CO profile does not indicate the phasing of the LTHR, which is vital as one would like to have surrogates that undergo LTC, NTC and HTC for the same temperatures and pressure as the real gasoline fuel.

PRF surrogates demonstrate the same reactivity as their respective FACE fuels at all compression ratios. They also capture the transitions of reactivity regimes quite accurately. The actual quantity of CO present in the exhaust signifies the amount of low temperature heat release, which is quite similar for all the fuels as equal amounts of fuel carbon is converted to products.

\section{Phasing of LTHR}

The computed LTHR of PRF 70 is presented in Fig. 4. The amount of LTHR increases with increasing compression ratio. The start of the low temperature reactivity also advances to an earlier point in the cycle as the temperature and pressure conditions for LTC occurs earlier in the cycle. The increasing temperature and pressure leads the fuel/air mixture in to NTC region of reactivity, thereby suppressing further heat release. At the lower compression, ratios the temperatures and pressures do not get high enough for the reactivity to transcend into the HTC region. The hot ignition finally occurs at CR 8.2 as the end gas temperature and pressure is high enough for the combustible mixture to overcome the NTC region and finally undergo autoignition. The heat release associated with the hot ignition is quite rapid due to the nature of HCCI combustion mode.

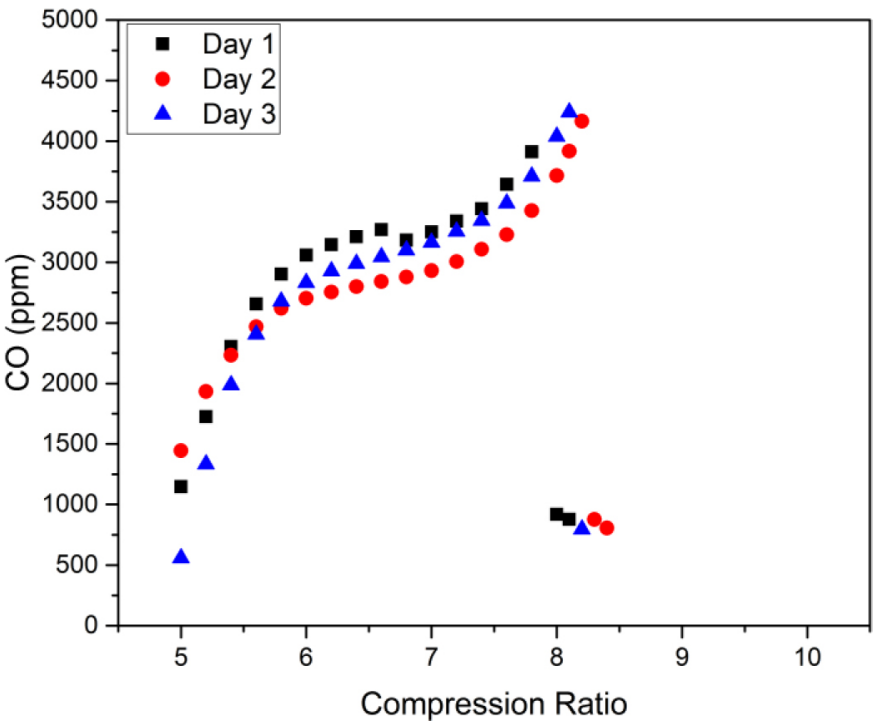

Figure 3.c. CO profiles of PRF 70 measured on three days. Start of Hot Ignition varies each day

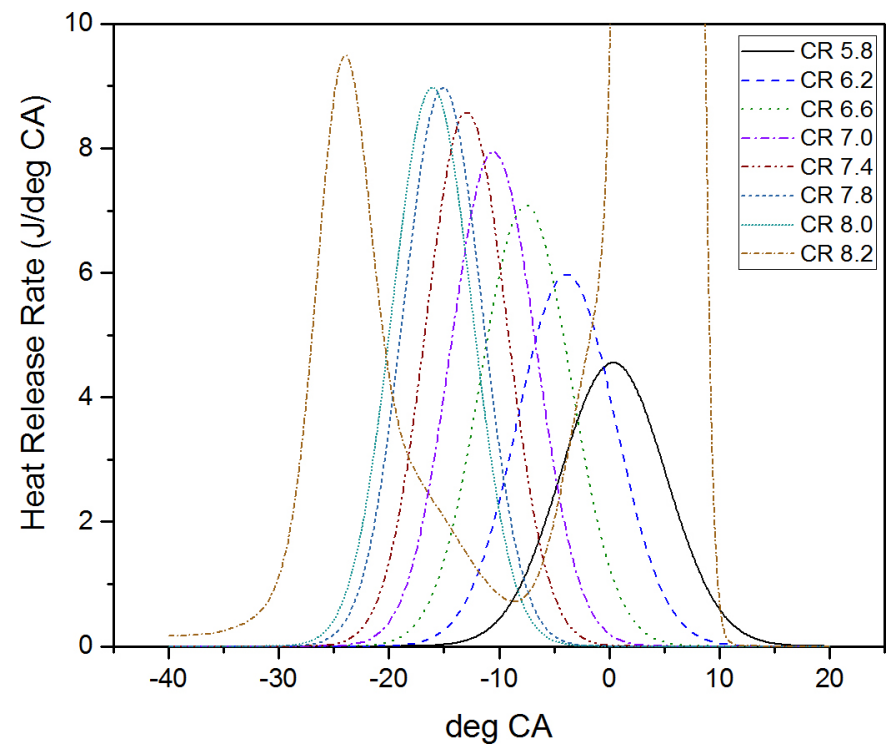

Figure 4. Computed Heat Release Rate of PRF 70 from engine pressure data 
As stated previously, the phasing of the LTHR is quite important in verifying whether the gasoline fuel and its surrogate have the same temperature and pressure distribution within their reactivity regimes. The phasing was evaluated from the normalized cumulative LTHR obtained by dividing the cumulative LTHR at each point by the total cumulative LTHR. Figure 5 presents the normalized cumulative LTHR of PRF 70 at CR 6.6. The crank angle at which $50 \%$ of the LTHR is released, CA50, is utilized as the comparison parameter.

The phasing of the LTHR of FACE gasoline fuels and their PRF surrogates are presented in Fig. 6.a and Fig. 6.b in the form of CA50 at different compression ratios. PRF surrogates have slightly advanced phasing than their respective FACE fuels, and this difference is consistent at all compression ratios. This may arise due to the presence of a greater amount of n-heptane in the PRFs than the FACE gasoline fuels, which exhibits its low temperature chemistry (LTC) at slightly lower temperatures.

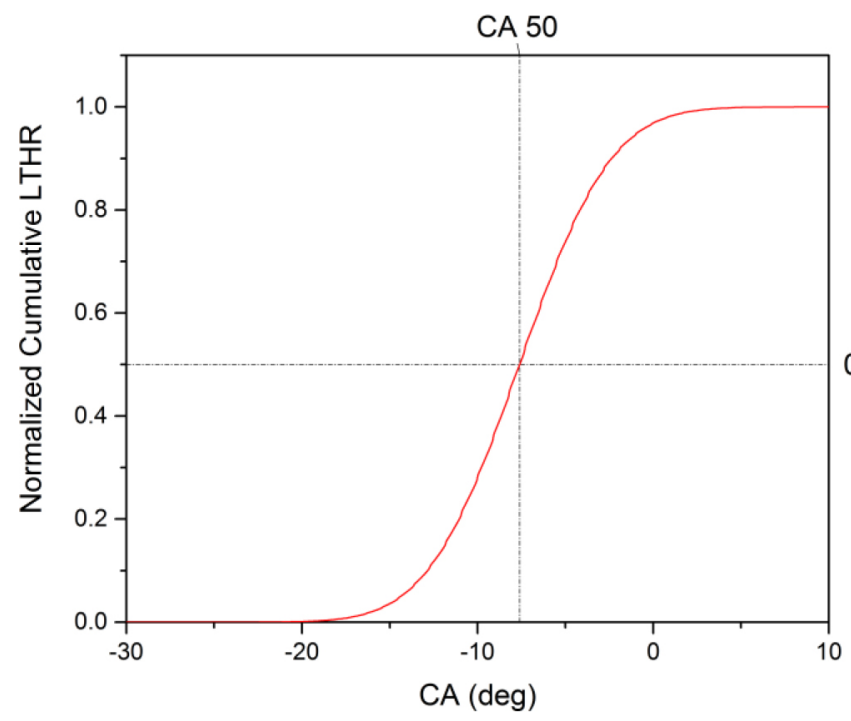

Figure 5. Normalized Cumulative Low Temperature Heat and the point indicating CA50 of PRF 70 at CR 6.6

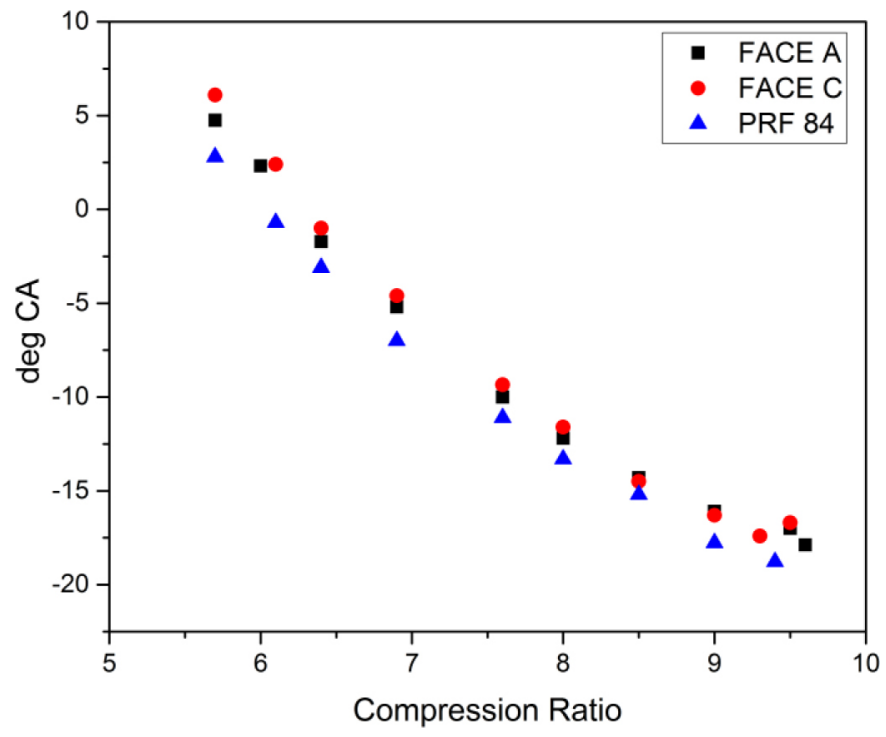

Figure 6.a. CA50 of LTHR FACE A, C, and PRF 84 at different compression ratios
The deviation in the LTC ignition elucidated in Sarathy et al.[24] does not seem to affect the ability of the PRF surrogates to replicate oxidation behavior, and the LTHR of the gasoline fuels with the same octane quality in an engine. This is due to the reduced amount of time spent by the fuel/air mixture at temperatures where the greatest differences in reactivity was exhibited in the ignition delay experiments. The LTC in the CFR engine experiments occurs at temperatures higher than $800 \mathrm{~K}$ for FACE A, C and PRF 84. Figure 6. demonstrates this via the bulk gas temperature at two different compression ratios for FACE A. The CA50 of the LTHR at these compression ratios is marked. Temperatures during which LTHR occurs is closely matched and around $850 \mathrm{~K}$. There were no discrepancies in the IDT observed at these temperatures by Sarathy et al. [24]

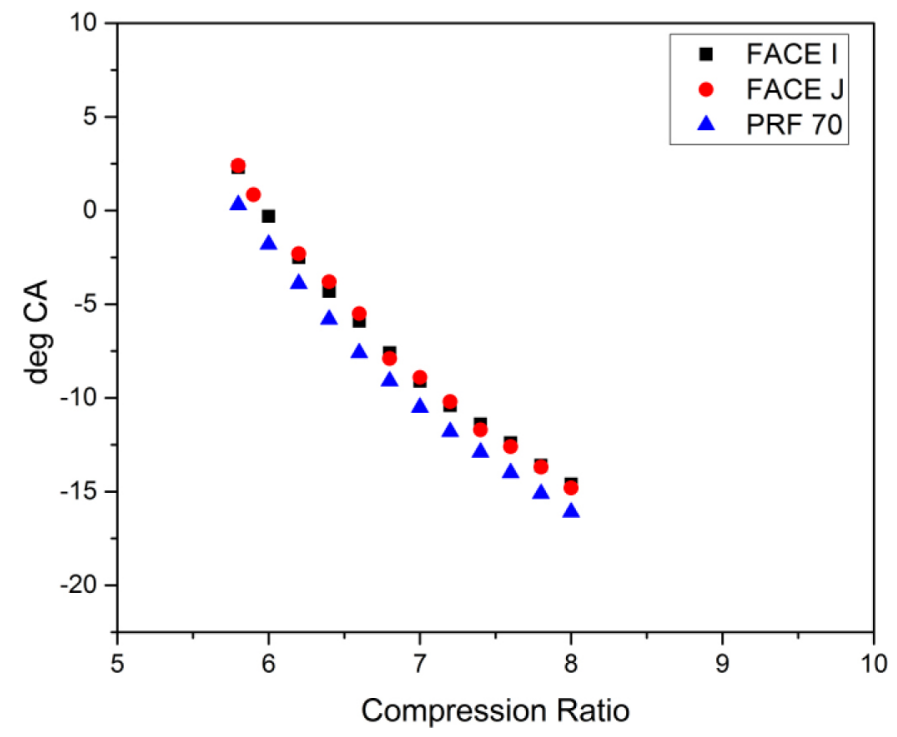

Figure 6.b. CA50 of LTHR ACE I, J, along with PRF 70 at different compression ratios

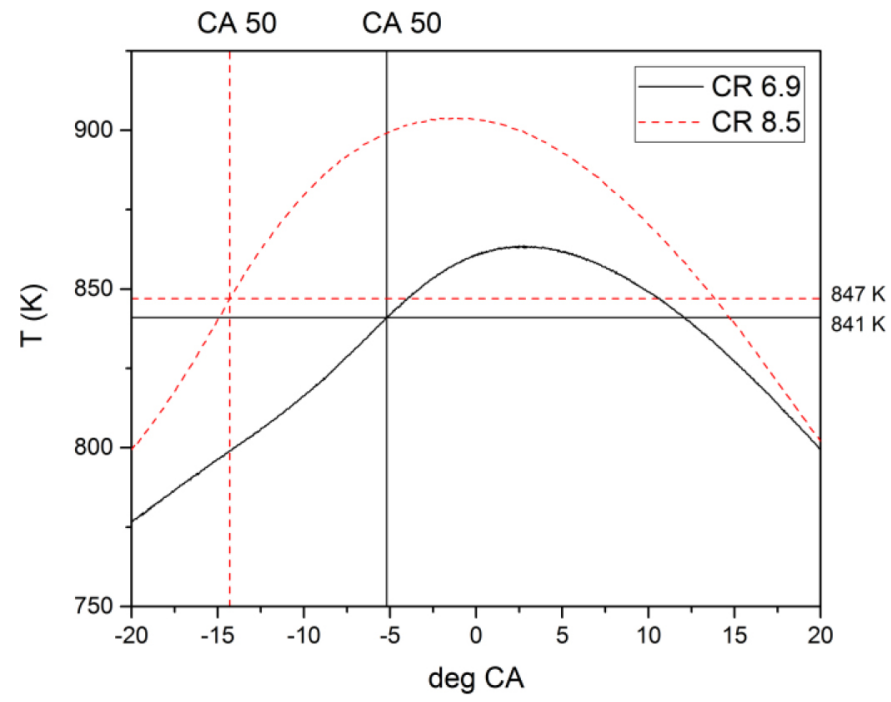

Figure 7. Bulk Gas Temperatures of FACE A at two compression ratios. The lines indicate the CA50 of the LTHR and the respective temperatures 


\section{Possibility of Surrogate Mixtures with Lower Molecular Weight Components}

The comparisons above revealed that the use of PRF surrogates based on RON appears to be adequate for reproducing low temperature gas phase reactivity of gasoline fuels with very small sensitivity. Indeed, if octane quality is a sufficient indicator of gas phase reactivity across the LTC, NTC and HTC regimes, then the possibility of using surrogate mixtures made of lower molecular weight hydrocarbons such as C1-C4 - alkanes, olefins, and alcohols which match the RON and MON would be attractive, since the uncertainty in the chemical kinetic mechanism as well as computational time can be reduced (due to the fewer number of species and reactions in the mechanism). These surrogates, if found to have the same reactivity of gasoline fuels with the same octane quality, could replace more complex PRF and TRF surrogates (ternary mixtures of n-heptane, iso-octane, and toluene).

The ignition delay simulations of two such surrogates with RON of 84 along with PRF 84 from $600 \mathrm{~K}$ to $1250 \mathrm{~K}$ in air, at pressures of 20 ,

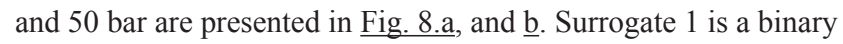
mixture of n-butane (69.90 mol.\%) and n-pentane (30.10 mol. \%) while Surrogate 2 consists of n-pentane (72.87 mol. \%) and 2-methylbutane (27.13 mol. \%). The RON of the mixtures was computed by linear-bymole blending as suggested in Ref. [28]. The RON of butane, npentane and 2-methylbutane were taken to be 93.6, 61.7 , and 92.3, respectively $[\underline{48}, \underline{49}]$. These chemical species were chosen due to their small sensitivities which makes them suitable for the FACE fuels discussed in this work. Hydrocarbons with even fewer carbon atoms exhibit large sensitivities as they do not exhibit NTC behavior and would be suitable for gasoline fuels with higher RON and sensitivities. The IDT simulations of PRF 82, and PRF 86 are also presented in the figures in order to identify the extent of deviation between PRF 84 and the new surrogate mixtures.

The discrepancies between PRFs is minor at low temperatures, and almost non-existent at higher temperatures. The temperature regimes of LTC, NTC and HTC are closely matched. Surrogates 1 and 2 are less reactive than even PRF 86 at temperatures corresponding to the region where low temperature chain branching chemistry drives reactivity. The onset of NTC and HTC is at a much greater temperature for these lower molecular weight surrogates. However, they are more reactive in the NTC, and less reactive in the HTC region.

The surrogates with lower molecular weight components do not match the reactivity of PRF 84 but the differences in IDT are within a factor of 2. The actual RON of the mixtures might be different from that obtained from linear molar blending leading to the observed discrepancies. The RON of these mixtures should therefore be experimentally determined. The effect of equivalence ratio might be another factor for the variations observed, since the RON and MON tests are typically conducted at slightly rich mixture conditions $(\varnothing>1)$ [50], while HCCI/PCCI combustion exclusively operates with excess oxygen inside the cylinder. The uncertainty in the predictions of the kinetic models might be another contributing factor.
The chemistry of surrogates with lower molecular weight components is markedly different from those of PRFs with similar RONs.

Nonetheless, these surrogates show potential for simulating the gas phase reactivity of low sensitivity gasoline fuels, since several factors other than differences in chemical kinetics could have given rise to the parities observed as discussed. However, further experimental investigations are required to address these uncertainties. The performance of these surrogates could be investigated with a similar experimental technique discussed in this work. The influence of varying equivalence ratio and intake air pressures also require further investigation. The effect of recirculation (EGR) could be included to increase the confidence in the surrogate mixtures for use in $\mathrm{HCCI} /$ PCCI engine simulations as most strategies for their operation include its use.

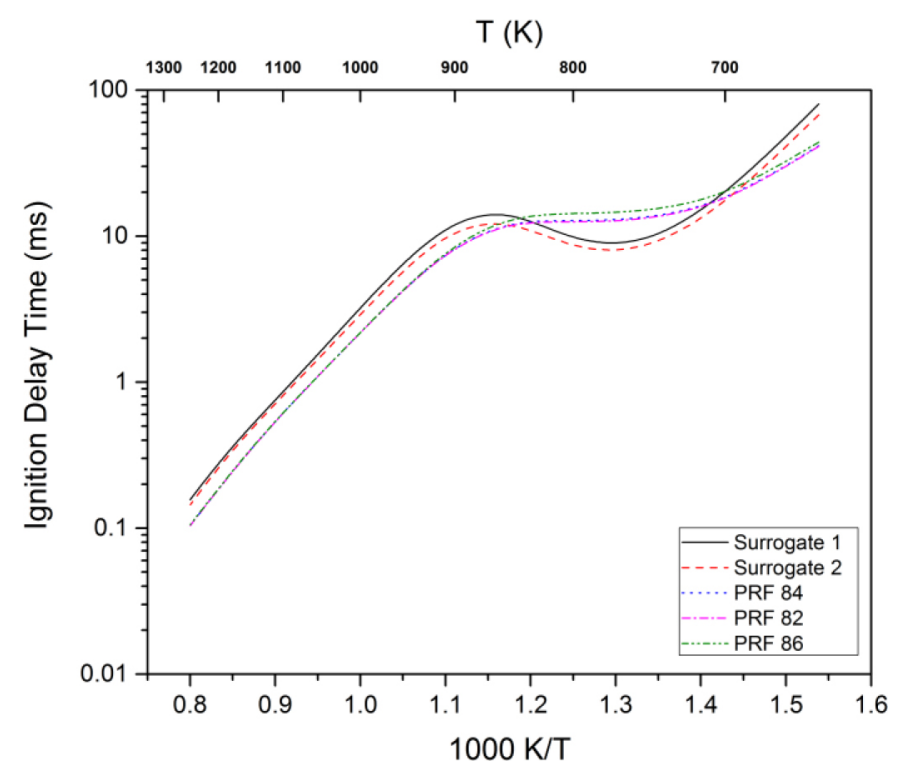

Figure 8.a. Ignition Delay Time simulations for new surrogates and PRFs at $20 \mathrm{bar}$

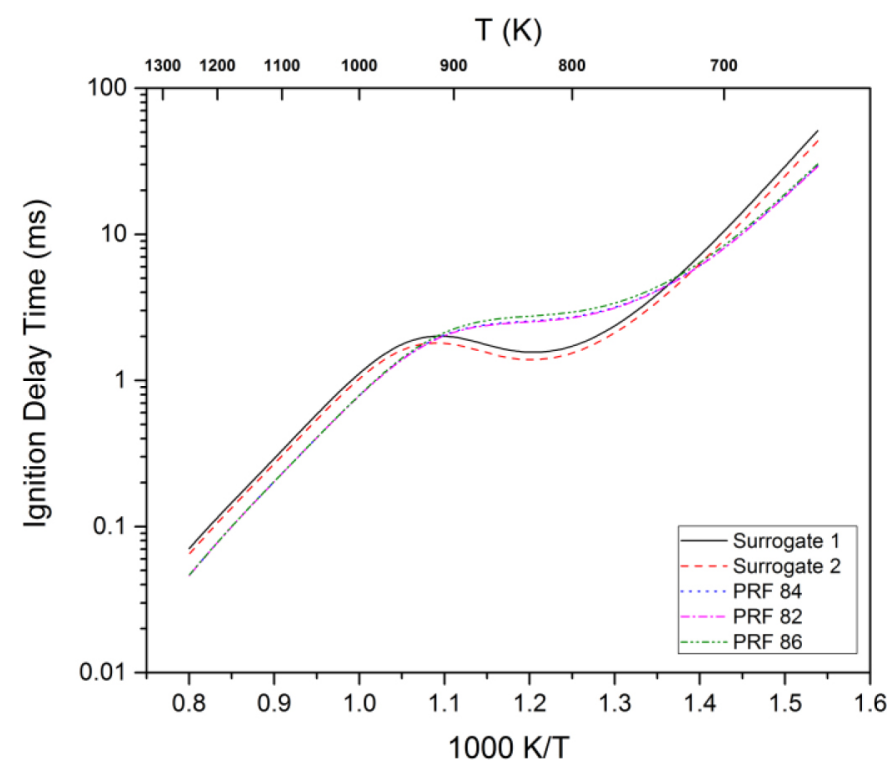

Figure 8.b. Ignition Delay Time simulations for new surrogates and PRFs at 50 bar 


\section{Summary/Conclusions}

- The use of RON as a basis for choosing surrogates for simulation of gas phase kinetics, especially for gasoline fuels with low sensitivities, appears adequate for the experimental conditions tested. The quanta and phasing of low temperature heat release, as well as the onset of hot ignition of the complex gasoline fuels was well reproduced by PRF surrogates. By extension, the OI could be a sufficient criterion for surrogate formulation for gasoline fuels with different RONs and MONs. However, the use of surrogates formulated based on the above criterion for combustion simulations involving complex physical phenomenon such as spray, mixing and diffusion requires further investigation before these recommendations can be made with confidence.

- The possibility of adopting RON based surrogates for gas phase simulations with lower molecular weight hydrocarbon molecules also requires further investigation. Such surrogates would reduce computational time as well as uncertainty within the kinetic model, since the rate parameters are easier to determine for such molecules.

\section{References}

1. Epping, K., Aceves, S., Bechtold, R., and Dec, J., "The Potential of HCCI Combustion for High Efficiency and Low Emissions," SAE Technical Paper 2002-01-1923, 2002, doi:10.4271/200201-1923.

2. Stanglmaier, R. and Roberts, C., "Homogeneous Charge Compression Ignition (HCCI): Benefits, Compromises, and Future Engine Applications," SAE Technical Paper 1999-013682, 1999, doi:10.4271/1999-01-3682.

3. Dec, J., "A Computational Study of the Effects of Low Fuel Loading and EGR on Heat Release Rates and Combustion Limits in HCCI Engines," SAE Technical Paper 2002-01-1309, 2002, doi:10.4271/2002-01-1309.

4. Dec, J. and Sjöberg, M., "Isolating the Effects of Fuel Chemistry on Combustion Phasing in an HCCI Engine and the Potential of Fuel Stratification for Ignition Control," SAE Technical Paper 2004-01-0557, 2004, doi:10.4271/2004-01-0557.

5. Sjöberg, M. and Dec, J., "Influence of Fuel Autoignition Reactivity on the High-Load Limits of HCCI Engines," SAE Int. J. Engines 1(1):39-58, 2009, doi:10.4271/2008-01-0054.

6. Sjöberg, M. and Dec, J., "Smoothing HCCI Heat-Release Rates Using Partial Fuel Stratification with Two-Stage Ignition Fuels," SAE Technical Paper 2006-01-0629, 2006, doi:10.4271/200601-0629.

7. Sjöberg, M. and Dec, J., "EGR and Intake Boost for Managing HCCI Low-Temperature Heat Release over Wide Ranges of Engine Speed," SAE Technical Paper 2007-01-0051, 2007, doi: $10.4271 / 2007-01-0051$.
8. Sjöberg, M., Dec, J., Babajimopoulos, A., and Assanis, D., "Comparing Enhanced Natural Thermal Stratification Against Retarded Combustion Phasing for Smoothing of HCCI HeatRelease Rates," SAE Technical Paper 2004-01-2994, 2004, doi:10.4271/2004-01-2994.

9. Sjöberg, M., Dec, J.E., “An investigation into lowest acceptable combustion temperatures for hydrocarbon fuels in HCCI engines," Proc. Combust. Inst. 30:2719-26, 2005, doi: 10.1016/j.proci.2004.08.132.

10. Sjöberg, M., Dec, J.E., “Comparing late-cycle autoignition stability for single- and two-stage ignition fuels in HCCI engines," Proc. Combust. Inst. 31:2895-902, 2007, doi: 10.1016/j.proci.2006.08.010.

11. Mo, Y., "HCCI Heat Release Rate and Combustion Efficiency: A Coupled KIVA Multi-Zone Modelling Study,” Thesis, 2008.

12. Andrae, J.C.G., Head, R.A., "HCCI experiments with gasoline surrogate fuels modeled by a semidetailed chemical kinetic model," Combust. Flame 156:842-51, 2009, doi: 10.1016/j. combustflame.2008.10.002.

13. Ranzi, E., "A wide-range kinetic modeling study of oxidation and combustion of transportation fuels and surrogate mixtures," Energy and Fuels 20:1024-32, 2006, doi:10.1021/ef060028h.

14. Pitz, W., Cernansky, N., Dryer, F., Egolfopoulos, F. et al., "Development of an Experimental Database and Chemical Kinetic Models for Surrogate Gasoline Fuels," SAE Technical Paper 2007-01-0175, 2007, doi:10.4271/2007-01-0175.

15. Dooley, S., Won, S.H., Heyne, J., Farouk, T.I., et al., "The experimental evaluation of a methodology for surrogate fuel formulation to emulate gas phase combustion kinetic phenomena," Combust Flame 159:1444-66, 2012, doi: 10.1016/j.combustflame.2011.11.002.

16. Ahmed, A., Goteng, G., Shankar, V.S.B., Al-Qurashi, K., et al., "A computational methodology for formulating gasoline surrogate fuels with accurate physical and chemical kinetic properties," Fuel 143:290-300, 2015, doi: 10.1016/j. fuel.2014.11.022.

17. Andrae, J.C.G., "Development of a detailed kinetic model for gasoline surrogate fuels," Fuel 87:2013-22, 2008, doi: 10.1016/j.fuel.2007.09.010.

18. Kukkadapu, G., Kumar, K., Sung, C.J., Mehl, M., et al., "Experimental and surrogate modeling study of gasoline ignition in a rapid compression machine," Combust. Flame 159:3066-78, 2012; doi: 10.1016/j.combustflame.2012.05.008.

19. Mehl, M., Pitz, W.J., Westbrook, C.K., Curran, H.J., "Kinetic modeling of gasoline surrogate components and mixtures under engine conditions," Proc. Combust. Inst. 33:193-200, 2011, doi: 10.1016/j.proci.2010.05.027.

20. Pera, C., Knop, V., "Methodology to define gasoline surrogates dedicated to auto-ignition in engines," Fuel 96:59-69, 2012, doi: 10.1016/j.fuel.2012.01.008. 
21. Puduppakkam, K., Liang, L., Naik, C., Meeks, E. et al., "Combustion and Emissions Modeling of a Gasoline HCCI Engine Using Model Fuels," SAE Technical Paper 2009-010669, 2009, doi: 10.4271/2009-01-0669.

22. Wang, Y., Yao, M., Zheng. Z., "A semi-detailed chemical kinetic model of a gasoline surrogate fuel for internal combustion engine applications," Fuel 113:347-56, 2013, doi: 10.1016/j. fuel.2013.05.076.

23. Zhong, B.J., Zheng, D., "A chemical mechanism for ignition and oxidation of multi-component gasoline surrogate fuels," Fuel 128:458-66, 2014, doi: 10.1016/j.fuel.2014.03.044.

24. Sarathy, S.M., Kukkadapu, G., Mehl, M., Wang, W., et al., "Ignition of alkane-rich FACE gasoline fuels and their surrogate mixtures," Proc. Combust. Inst. 35:249-57, 2015, doi: 10.1016/j. proci.2014.05.122.

25. Westbrook, C.K., Warnatz, J., Pitz, W.J., “A detailed chemical kinetic reaction mechanism for the oxidation of iso-octane and n-heptane over an extended temperature range and its application to analysis of engine knock," Symp. Combust. 22:893-901, 1989 doi:10.1016/S0082-0784(89)80098-0.

26. Mehl, M., Pitz, W., Sjöberg, M., and Dec, J., "Detailed Kinetic Modeling of Low-Temperature Heat Release for PRF Fuels in an HCCI Engine," SAE Technical Paper 2009-01-1806, 2009, doi: 10.4271/2009-01-1806.

27. Tsurushima, T., "A new skeletal PRF kinetic model for HCCI combustion," Proc. Combust. Inst. 32(2):2835-41, 2009, doi: 10.1016/j.proci.2008.06.018.

28. Tanaka, S., Ayala, F., Keck, J.C., "A reduced chemical kinetic model for HCCI combustion of primary reference fuels in a rapid compression machine," Combust. Flame 133:467-81, 2003, doi:10.1016/S0010-2180(03)00057-9.

29. Ra, Y., Reitz, R.D., “A reduced chemical kinetic model for IC engine combustion simulations with primary reference fuels," Combust. Flame 155:713-38, 2008, doi: 10.1016/j. combustflame.2008.05.002.

30. ASTM D2699-13b, Standard Test Method for Research Octane Number of Spark-Ignition Engine Fuel, 2013, doi:10.1520/ D2699.

31. Kalghatgi, G., "Fuel Anti-Knock Quality - Part I. Engine Studies," SAE Technical Paper 2001-01-3584, 2001, doi:10.4271/2001-01-3584.

32. Mittal, V., Heywood, J.B., "The Relevance of Fuel RON and MON to Knock Onset in Modern SI Engines," SAE Technical Paper 2008-01-2414, 2008, doi:10.4271/2008-01-2414.

33. ASTM D2700-14, Standard Test Method for Motor Octane Number of Spark-Ignition Engine Fuel, 2014, doi:10.1520/ D2700-14.

34. Chang, J., Viollet, Y., Amer, A., Kalghatgi, G., "Fuel Economy Potential of Partially Premixed Compression Ignition (PPCI) Combustion with Naphtha Fuel," SAE Technical Paper 201301-2701, 2013, doi:10.4271/2013-01-2701.
35. Sahetchian, K.A., Blin, N., Rigny, R., Seydi, A., et al., "The oxidation of n-butane and n-heptane in a CFR engine Isomerization reactions and delay of autoignition," Combust. Flame 79:242-9, 1990, doi:10.1016/0010-2180(90)90136-F.

36. Leppard, W.R., "The Chemical Origin of Fuel Octane Sensitivity," SAE Technical Paper 902137, 1990, doi: $10.4271 / 902137$.

37. Leppard, W.R., "The Autoignition Chemistry of n-Butane: An Experimental Study", SAE Technical Paper 872150, 1987, doi: $\underline{10.4271 / 872150 .}$.

38. Yang, Y., Boehman, A.L., "Experimental study of cyclohexane and methylcyclohexane oxidation at low to intermediate temperature in a motored engine," Proc. Combust. Inst. 32:41926, 2009, doi: 10.1016/j.proci.2008.06.162.

39. Yang, Y., Boehman, A.L., "Oxidation chemistry of cyclic hydrocarbons in a motored engine: Methylcyclopentane, tetralin, and decalin," Combust. Flame 157:495-505, 2010, doi: 10.1016/j.combustflame.2009.08.011.

40. Yang, Y., Boehman, A.L., Simmie, J.M., "Uniqueness in the low temperature oxidation of cycloalkanes," Combust. Flame 157:2357-68, 2010, doi: 10.1016/j.combustflame.2010.06.005.

41. Zhang, Y., Boehman, A.L., "Autoignition of binary fuel blends of n-heptane and C7 esters in a motored engine," Combust. Flame 159:1619-30, 2012, doi: 10.1016/j. combustflame.2011.11.019.

42. Zhang, Y., Boehman, A.L., "Oxidation of 1-butanol and a mixture of n-heptane/1-butanol in a motored engine," Combust. Flame 157:1816-24, 2010, doi: 10.1016/j. combustflame.2010.04.017.

43. Mcbride, J., Reno, A., "Coefficients for calculating thermodynamics and transport properties of individual species," NASA Technical Memorandum 4513, 1999.

44. Soyhan, H.S., Yasar, H., Walmsley, H., Head, B., et al., "Evaluation of heat transfer correlations for HCCI engine modeling," Appl. Therm Eng. 29:541-549, 2009, doi: 10.1016/j. applthermaleng.2008.03.014.

45. CRC Report No. AVFL-24, "FACE GASOLINES AND BLENDS WITH ETHANOL: DETAILED CHARACTERIZATION OF PHYSICAL AND CHEMICAL PROPERTIES," 2014.

46. CHEMKIN-PRO 15131, 2013.

47. Bugler, J., Somers, K.P., Silke, E.J., Curran, H.J., "Revisiting the Kinetics and Thermodynamics of the Low-Temperature Oxidation Pathways of Alkanes: A Case Study of the Three Pentane Isomers," J. Phys. Chem. A 119:7510-7527, 2015, doi: 10.1021/acs.jpca.5b00837.

48. Perdih, A., Perdih, F., "Chemical interpretation of octane number," Acta. Chim. Slov. 53:306-315, 2006.

49. Ghosh, P., Hickey, K.J., Jaffe, S.B., "Development of a Detailed Gasoline Composition-Based Octane Model," Ind. Eng. Chem. Res. 45:337-345, 2006, doi:10.1021/ie050811h.

50. Morganti, K., Foong, T.M., Brear, M., Da Silva, G., et al., "Design and Analysis of a Modified CFR Engine for the Octane Rating of Liquefied Petroleum Gases (LPG)," SAE Technical Paper 2014-01-14, 2014, doi:10.4271/2014-01-1474. 


\section{Contact Information}

Corresponding Author: Mani Sarathy

mani.sarathy@kaust.edu.sa

\section{Acknowledgments}

The authors wish to thank Adrian Ichim for performing the engine experiments. This work was supported by KAUST and the Saudi Aramco FUELCOM program.

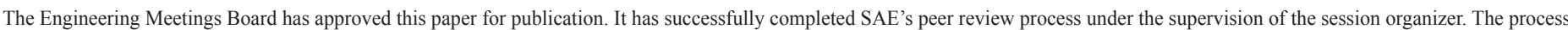
requires a minimum of three (3) reviews by industry experts.

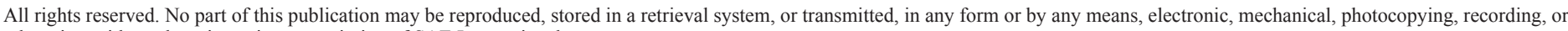
otherwise, without the prior written permission of SAE International.

Positions and opinions advanced in this paper are those of the author(s) and not necessarily those of SAE International. The author is solely responsible for the content of the paper.

ISSN 0148-7191

http://papers.sae.org/2016-01-0748 